\title{
EDITORIAL SUMMARY.
}

In the American Naturalist for September we find two very interesting papers on Entomological subjects. The first, by Prof. C. V. Riley, on "Controlling Sex in Butterflies," in which he shows, we think pretty conclusively, by the results of a number of experiments which he has instituted, that the theory advanced by Mrs. M. Treat in the March number of the Naturalist, to the effect that the relative proportions in the sexes of butterflies can be controlled by the quantity of food given, is untenable. Mrs. Treat contended that by half starving a brood of larva you would obtain as a result either exclusively males or a very large proportion of such, while by liberal feeding the reverse would be the case, the gentler sex greatly preponderating. Prof. Riley thus sums up his results: "On the whole, if these experiments indicate anything, they indicate that where more males than females are obtained from stinted arvæ, it is attributable to the fact that the females, being largest and requiring most nourishment, succumb most readily under such treatment ; rather than that the sexual characteristics are modified and determined by such treatment."

The second paper is the "Third Annal Report on the Injurious and Beneficial Insects of Massachusetts," by A. S. Packard, Tr.

The author states that at a low estimate there are probably upwards of 50,000 species of insects in the United States, the proportions in the different families being roughly estimated as follows:- Hymenoptera (bees, wasps, ichneumon flies, sawflies, \&c.,) 1 0,000; Lepidoptera (butterflies and moths,) 5,000; Diptera (two-winged flies,) r 0,000; Coleoptera (beetles,) 10,c00; Hemiptera (bugs, \&c.,) 10,000, with several thousand species of Orthoptera (grasshoppers, \&c,) and Neuroptera (dragon flies, caddis flies, \&c.) A large number of these insects are as yet undescribed, so that in the mere determination, classification and arrangement of these vast hosts of animated creatures, an immense task has to be performed for which the present number of working Entomologists is entirely insufficient, there being, the author states, but about thirty in this country who publish anything relating to insects. Hence the more important work of studying the history and habits of the various species is necessarily very much interfered with. 
With regard to insectivorous birds it is said that they seem to have certain fancies of their own as to what they will eat among insects. The canker-worm, which appears to be avoided by most birds, is eaten in large numbers by doves, and the martin will store up in its nest quarts of the common striped beetle of the potato, to the exclusion of other insects.

Some interesting details are given in reference to the history and mode of life of the May Bug, Lachnosterna fusca, and also the Goldsmith Beetle, Cotalpa lanigera, both destructive to the roots of the strawberry. The Bean Weevil, an insect which seems to be largely on the increase in New England, is noticed, and some suggestions given in regard to checking its further spread. The seventeen year Locust and other species of Locusts are also referred to, as well as several other less injurious as well as beneficial insects.

A Distinguished French Visitor.-At the September gth meeting of the Philadelphia Academy of Natural Sciences, among the distinguished visitors present were Prof. C. V. Riley, of St. Louis, and Dr. J. E. Planchon, professor of botany at Montpellier in France, the latter of whom is now in this country under authority of the French Government, to investigate our grape diseases. By invitation of the President, Dr. Ruschenber, Prof. Riley gave an account of the Phylloxera or grape vine root-louse, with his most recent discoveries in regard to the same. He had little doubt but the insect was at the root of most diseases that attack the grape in this country, as it was certainly in Europe. Prof. Leidy inquired of Mr. Riley the true position of the insect in scientific classification ; Prof. Riley replied that it was not yet well settled. Its appearance brought it somewhere near the aphids, but it did not have successive broods from one impregnation; aphids did. In this respect it approaches Coccus. He thought it between the two families.

Prof. Planchon described the ravages of the insect on the grape-roots in France, and thought them less destructive on the roots of American species of grapes than the European; and one of the objects of his mission was to ascertain this fact definitely, so that in Europe some American vines might be used as stocks for their vineyards.

It was clear from the fact that the European vines had been but recently attacked by it, and had suffered so severely from it; while in America-the home of the insect-the wild vines had done tolerably well 
for so many ages, that the Vitis vinifera with it was more of a favorite. He excused himself from any lengthy remarks on account of his limited English, and would briefly say that he agreed entirely with Prof. Riley's views regarding it.

Mr. Thomas Meehan gave a history of grape-culture and grape-diseases in Pennsylvania from the earliest time to the present, and showed that the failures had never been satisfactorily explained on any theory sometimes given, such as change of climate, or depletion of the soil. There were always some facts or figures which rendered every previous theory inadmissable to his mind, as he had frequently stated in other places. Prof. Riley's insect discovery, however, met all the requirements of the case, so as to give an air of possibility to Mr. Riley's views, such as no other theory has possessed. That when we saw the foreign grape and others which often did perfectly well for years in one locality, and then failed, it seemed absurd to suppose that the climate or soil suddenly gave out; but a sudden incursion of a brood of root-insects was a cause that could have such a sudden effect.-Gardiener's Monthly.

LEAF-CUTTER BeE.-For five summers a rose-leaf-cutter bee has built her nest in a narrow-spouted watering-pot in my garden, and I have just heard of another nest, found in the touch-hole of a gun belonging to our volunteer artillery. My books on entomology only mention these bees' nests as found in earth or cavities of walls; therefore I venture to record the above as rather unusual localities.-- J. C. in Hardwicke's Science Gossip.

\section{ADVERTISEMENTS.}

EXCHANGE. - I am desirous to exchange English for Canadian or American Lepidoptera. I should also be glad to exchange living pupa of many British Lepidoptera for pupe of American species. J. C. Wasserman, Beverly Terrace, Cullercoats, North Shields, England.

Coleoptera for SAle.-A number of Rocky Mountain Coleoptera will soon be for sale in sets by John Akhurst, I 9 Prospect Street, Brooklyn, N. Y. 